\title{
Biomassa e comprimento de raízes finas em uma área de restauração florestal
}

\section{Claudinei Garlet ${ }^{1}$ e Mauro Valdir Schumacher ${ }^{2}$}

\author{
${ }^{1}$ Universidade Federal de Santa Maria. Centro de Ciências Rurais. Programa de Pós- \\ Graduação em Engenharia Florestal. Camobi. Santa Maria-RS, Brasil (CEP 97105- \\ 900). E-mail: claudineigarlet@gmail.com. \\ ${ }^{2}$ Universidade Federal de Santa Maria. Centro de Ciências Rurais. Departamento de \\ Ciências Florestais. Camobi. Santa Maria-RS, Brasil (CEP 97105-900).
}

Resumo. Em ambientes naturais as raízes finas $(<2,0 \mathrm{~mm})$ são responsáveis pela absorção de água e nutrientes, sendo fundamentais na manutenção dos ecossistemas. Nas áreas em processo de recuperação, a dinâmica dessas raízes é afetada, pela constante alteração da composição fitossociológica nesses locais. Desta forma, o objetivo do presente estudo foi avaliar a biomassa e o comprimento de raízes finas em uma área de restauração florestal no Município de Santa Maria, Estado do Rio Grande do Sul, Brasil. Foram coletadas 18 amostras de solo, até $20 \mathrm{~cm}$, sendo estas divididas em quatro profundidades: 0-5, 5-10, 10-15 e $15-20 \mathrm{~cm}$. As raízes foram separadas do solo e, posteriormente, processadas para obtenção dos valores de biomassa e comprimento. Para os valores de biomassa e comprimento de raízes finas, obtiveram-se, respectivamente, 5,60 $\mathrm{Mg}^{\text {ha-1 }}$ e $104.435,81 \mathrm{~km} \mathrm{ha}^{-1}$, sendo que aproximadamente a metade concentra-se na camada de $0-5 \mathrm{~cm}$, diminuindo gradativamente com o aumento da profundidade. A alteração da fitossociologia local, principalmente pela introdução de espécies exóticas invasoras, alterou a dinâmica do sistema radicular local, elevando os valores de biomassa e comprimento de raízes finas.

Palavras-chave: Sistema radicular; Densidade de raízes; Espécies invasoras.

Abstract. Biomass and length of fine roots in a forest
restoration area. In natural environments, fine roots $(<2.0 \mathrm{~mm})$
are responsible for the absorption of water and nutrients, being
fundamental in the maintenance of ecosystems. In areas
undergoing recovery, the dynamics of these roots are affected by
the constant alteration of the phytosociological composition in
these locations. Thus, the objective of the present study was to
evaluate the biomass and the length of fine roots in a forest
restoration area in the Municipality of Santa Maria, Rio Grande do
Sul State, Brazil. Eighteen soil samples were collected, up to
$20 \mathrm{~cm}$, which were divided into four depths: $0-5,5-10,10-15$ and
$15-20$ cm. The roots were separated from the soil and
subsequently processed to obtain the biomass and length values.

Recebido $09 / 03 / 2020$

Aceito

$24 / 04 / 2020$

Publicado

$30 / 04 / 2020$

Acesso aberto

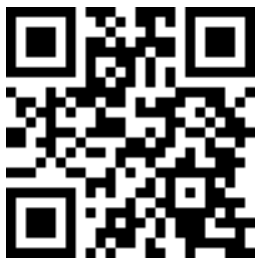

ORCID

(D) 0000-0001-6702-032X Claudinei Garlet

D 0000-0001-6926-6200

Mauro Valdir

Schumacher

ISSN 2359-1412/RBGAS-2020-0024/2020/7/15/25/351

Rev. Bras. Gest. Amb. Sustent.

http://revista.ecogestaobrasil.net 
For the values of biomass and length of fine roots, $5.60 \mathrm{Mg}^{\text {ha-1 }}$ and $104,435.81 \mathrm{~km} \mathrm{ha}^{-1}$ were obtained, respectively, with almost half being concentrated in the $0-5 \mathrm{~cm}$ layer, decreasing gradually with increasing depth. The alteration of local phytosociology, mainly by the introduction of invasive alien species, altered the dynamics of the local root system, increasing the values of biomass and length of fine roots.

Keywords: Root system; Root density; Invasive species.

\section{Introdução}

Em condições impostas pelo ambiente, as plantas, para se adaptarem, desenvolvem mecanismos visando sua instalação e sobrevivência, considerando as condições ambientais do ecossistema. Uma dessas adaptações diz respeito ao desenvolvimento do sistema radicular das espécies vegetais.

As raízes são mecanismos essenciais às plantas, pois atuam na absorção de água e nutrientes do solo, além de promoverem o ancoramento e a sustentação da árvore (Navroski et al., 2010). 0 desenvolvimento radicular é um processo complexo, controlado por características inerentes à própria planta e ao ambiente no qual ela se encontra inserido (Lopes et al., 2013). Segundo Gonçalves e Mello (2005), o principal fator envolvido na distribuição das raízes no solo é o genótipo da espécie, no entanto, essa distribuição pode estar associada à fatores edáficos, como fertilidade, densidade, disponibilidade hídrica, temperatura e pelas circunstâncias nas quais as espécies se desenvolvem, como, por exemplo, a competição entre árvores.

As atividades antrópicas vêm causando mudanças expressivas na composição de muitos ecossistemas florestais naturais (Wardle e Peltzer, 2017), fazendo com que as espécies de determinado local tenham que se adaptar de acordo com as alterações ocorridas nestes ambientes.

O transporte e introdução de espécies fora de suas faixas naturais de ocorrência possibilitam que, algumas delas, se tornem altamente invasivas nesses novos ambientes, comprometendo o desenvolvimento e a biodiversidade das espécies nativas desses locais (Richardson e Pyšek, 2012). Além disso, a presença de espécies exóticas pode influenciar as propriedades do solo (Peltzer, et al., 2016), afetar os estoques e os ciclos biogeoquímicos dos nutrientes (Hughes e Denslow, 2005; Vilà et al., 2011) e, consequentemente, alterar a dinâmica de raízes finas nesses ambientes.

Estudos relacionados às características do sistema radicular e dos princípios da sustentabilidade em florestas são importantes para o entendimento do equilíbrio ecológico desses ecossistemas, pois fornecem informações que irão servir para elucidar as interações fisiológicas básicas, sobretudo aquelas relacionadas à nutrição e ao balanço hídrico das árvores (Lopes et al., 2010).

O objetivo do presente estudo foi estimar a biomassa e o comprimento das raízes finas da vegetação de uma área de restauração florestal.

\section{Material e métodos}

\section{Área de estudo}

0 estudo foi conduzido em uma área de restauração florestal de aproximadamente 1,72 ha, pertencente ao Jardim Botânico da Universidade Federal de Santa Maria, nas coordenadas $29^{\circ} 43^{\prime} 8.89^{\prime \prime}$ S e $53^{\circ} 43^{\prime} 40.99^{\prime \prime}$ W (Figura 1). 


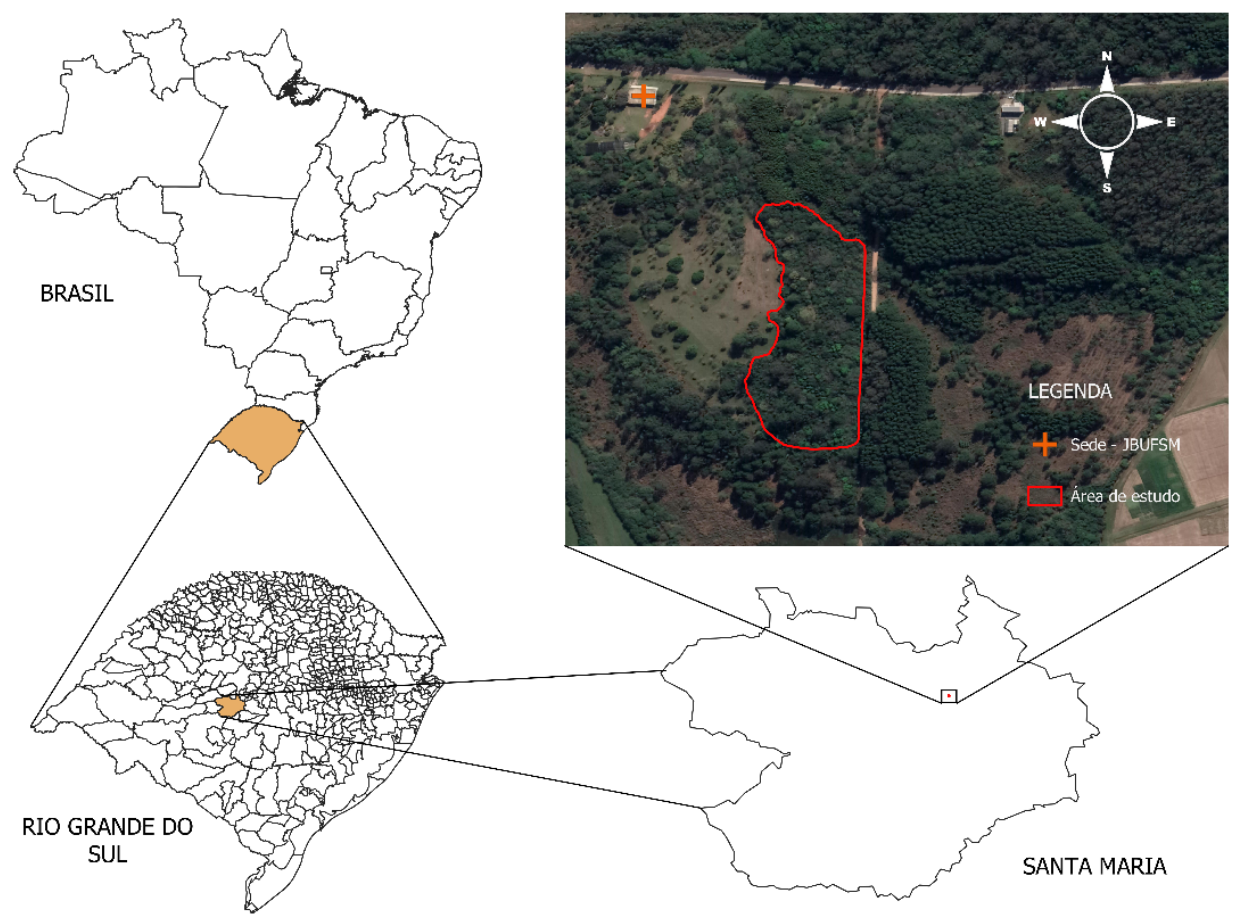

Figura 1. Localização da área de estudo, no município de Santa Maria-RS.

Segundo a classificação climática de Köppen, o clima da região é do tipo Cfa, onde a temperatura média anual é de $19^{\circ} \mathrm{C}$ e a precipitação média anual de $1.769 \mathrm{~mm}$ (Alvares et al., 2014). Além disso, a região apresenta chuvas bem distribuídas ao longo dos anos, conforme pode ser observado no diagrama climático (Figura 2).

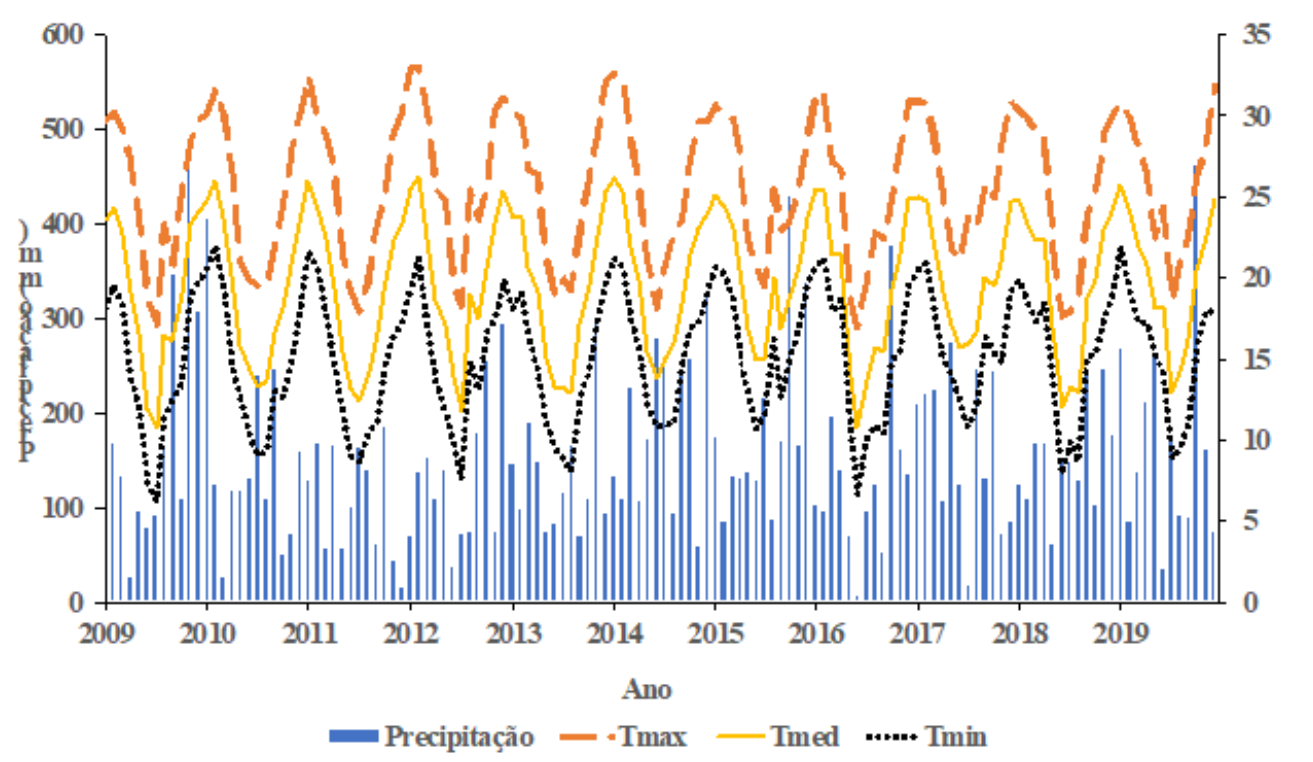

Figura 2. Diagrama climático para o município de Santa Maria-RS. Fonte: INMET (2020).

Rev. Bras. Gest. Amb. Sustent., 2020, vol. 7, n. 15, p. 351-361. 
A região possui relevo suavemente ondulado, com solos ácidos e saturação de bases baixa nos horizontes mais superficiais, aumentando estes valores em profundidade no perfil (NAVROSKI et al., 2010). Conforme Pedron et al., (2004), o Jardim Botânico da UFSM apresenta diferentes classes de solo, sendo que, no local de estudo, ocorre predominantemente o Alissolo Hipocrômico argilúvico (APt). As principais características desta classe de solo estão apresentadas na Tabela 1. A partir dos dados é possível analisar que neste tipo de solo há aumento da quantidade de argila em profundidade, bem como dos teores de $\mathrm{Al}^{3+}$ ao longo do perfil.

Tabela 1. Características morfológicas, físicas e químicas do solo na área de estudo.

\begin{tabular}{|c|c|c|c|c|c|c|c|c|}
\hline Solo & Horizonte & $\begin{array}{c}\text { pH } \\
\left(\mathbf{H}_{2} \mathbf{0}\right) \\
(1: 1)\end{array}$ & $\begin{array}{l}\text { CTC (pH 7) } \\
\left(\mathrm{cmol}_{\mathrm{c}} \mathrm{kg}^{-1}\right)\end{array}$ & $\begin{array}{c}\mathrm{Al}^{3+} \\
\left(\mathrm{cmol}_{\mathrm{c}} \mathrm{kg}^{-1}\right)\end{array}$ & $\begin{array}{c}\mathrm{V} \\
(\%)\end{array}$ & $\begin{array}{c}\text { Carbono } \\
\left.\left(g^{-1}\right)^{-1}\right)\end{array}$ & Drenagem & $\begin{array}{r}\text { Argila } \\
\left(\mathrm{g} \mathrm{kg}^{-1}\right)\end{array}$ \\
\hline \multirow{2}{*}{$\mathrm{APt}$} & A & 5,0 & 18,0 & 4,0 & 50 & 18,0 & $\begin{array}{c}\text { Bem } \\
\text { drenado }\end{array}$ & 320 \\
\hline & $\mathrm{B}$ & 4,9 & 34,0 & 16,0 & 40 & 11,6 & Moderado & 740 \\
\hline
\end{tabular}

Fonte: Pedron et al. (2004).

A vegetação do local apresenta em sua composição espécies da Floresta Estacional Decidual, tendo em vista que mais de $50 \%$ das árvores do estrato superior perdem as folhas na época desfavorável (Farias et al., 1994; Longhi et al., 2000). No entanto, devido, principalmente, à exploração agrícola e a introdução de espécies vegetais, pode-se observar alterações significativas na estrutura fitossociológica local quando comparada às suas características originais (Longhi et al., 2000; Santos et al., 2010).

Estas alterações favoreceram o desenvolvimento e a ocupação de determinados grupos de plantas, especialmente as espécies exóticas. Dentre essas espécies, destacam-se Pittosporum undulatum e Hovenia dulcis, que, em função do seu elevado potencial de invasão - característica essa associada à sua adaptação a diferentes habitats, alto percentual de crescimento e dispersão de sementes por zoocoria - ampliaram suas áreas de ocupação, tornando-as predominantes no local de estudo.

\section{Amostragem de raízes}

Para a coleta das amostras de solo, distribuiu-se, de forma aleatória, 18 pontos dentro da área de estudo. As amostras foram coletadas com o auxílio de um tubo coletor com diâmetro de 7,27 cm e divididas nas profundidades de 0-5, 5-10, 10-15 e 15-20 cm (Figura 3), totalizando 72 amostras, sendo estas armazenadas em sacos plásticos devidamente identificados.

As raízes foram separadas do solo por meio da lavagem com jatos d'água, onde se utilizaram duas peneiras, sendo uma de $2 \mathrm{~mm}$ e outra de $1 \mathrm{~mm}$. Após a lavagem, as raízes que ficaram nas peneiras foram separadas, permanecendo-se apenas aquelas com diâmetro inferior a $2 \mathrm{~mm}$. Para sua conservação, as raízes foram acondicionadas em potes identificados, contendo água destilada e álcool em solução 10\%, e armazenadas em geladeira a aproximadamente $5^{\circ} \mathrm{C}$. 


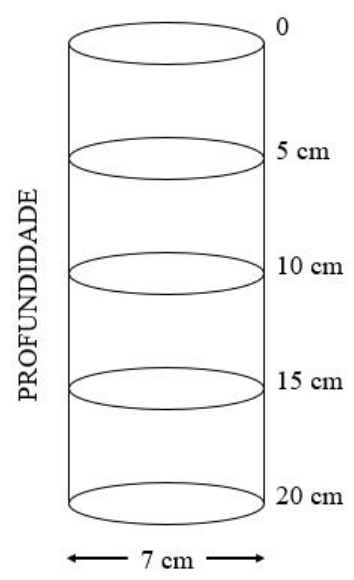

Figura 3. Detalhe do monólito de solo, ilustrando as divisões de $5 \mathrm{em} 5 \mathrm{~cm}$, até os $20 \mathrm{~cm}$ de profundidade. Fonte: Adaptado de Navroski et al. (2010).

Na sequência, distribuiu-se as raízes finas sobre uma folha branca, tomando-se o cuidado de não haver sobreposição umas com as outras, sendo estas fotografadas, posteriormente. Para processamento das imagens, utilizou-se o Software Image ${ }^{\circledR}$, que fornece os valores do perímetro das raízes. Para determinação do comprimento das raízes, considerou-se a metade de seus perímetros.

Após serem fotografadas, as raízes foram armazenadas em sacos de papel e colocadas em estufa de circulação de ar a $70{ }^{\circ} \mathrm{C}$, até o peso constante. Então, o material foi pesado em balança de precisão para determinação da massa seca de raízes e estimativa da biomassa por hectare.

\section{Análise dos dados}

Para avaliação das diferenças na massa de raízes finas nas distintas profundidades do solo, as médias foram comparadas pelo teste de Tukey a $5 \%$ de probabilidade de erro.

\section{Resultados e discussão}

\section{Densidade e biomassa de raízes finas}

Analisando a Figura 4, verifica-se que a densidade de raízes finas reduziu em profundidade no perfil do solo, passando de 5,29 para $1,40 \mathrm{~g} \mathrm{dm}^{-3}$ nas camadas de $0-5 \mathrm{~cm}$ e 15-20 cm, respectivamente. De acordo com Finér et al. (2011), a biomassa de raízes finas diminui exponencialmente da superfície às camadas mais profundas do solo, em diferentes biomas florestais.

A redução da densidade de raízes finas com o aumento da profundidade já foi observada em outros estudos (Witschoreck et al., 2003; Genet et al., 2010; Menezes et al., 2010; Paiva et al., 2011; Grant et al., 2012; Nogueira, 2013). Esta diminuição está atrelada, principalmente, à maior aeração e das maiores concentrações de matéria orgânica e nutrientes nas primeiras camadas de solo, além de, nas camadas mais profundas, haver maior adensamento e presença de rochas, que dificultam o desenvolvimento radicular (Navroski et al., 2010). 
Densidade $\left(\mathrm{g} \mathrm{dm}^{-3}\right)$ de raízes finas

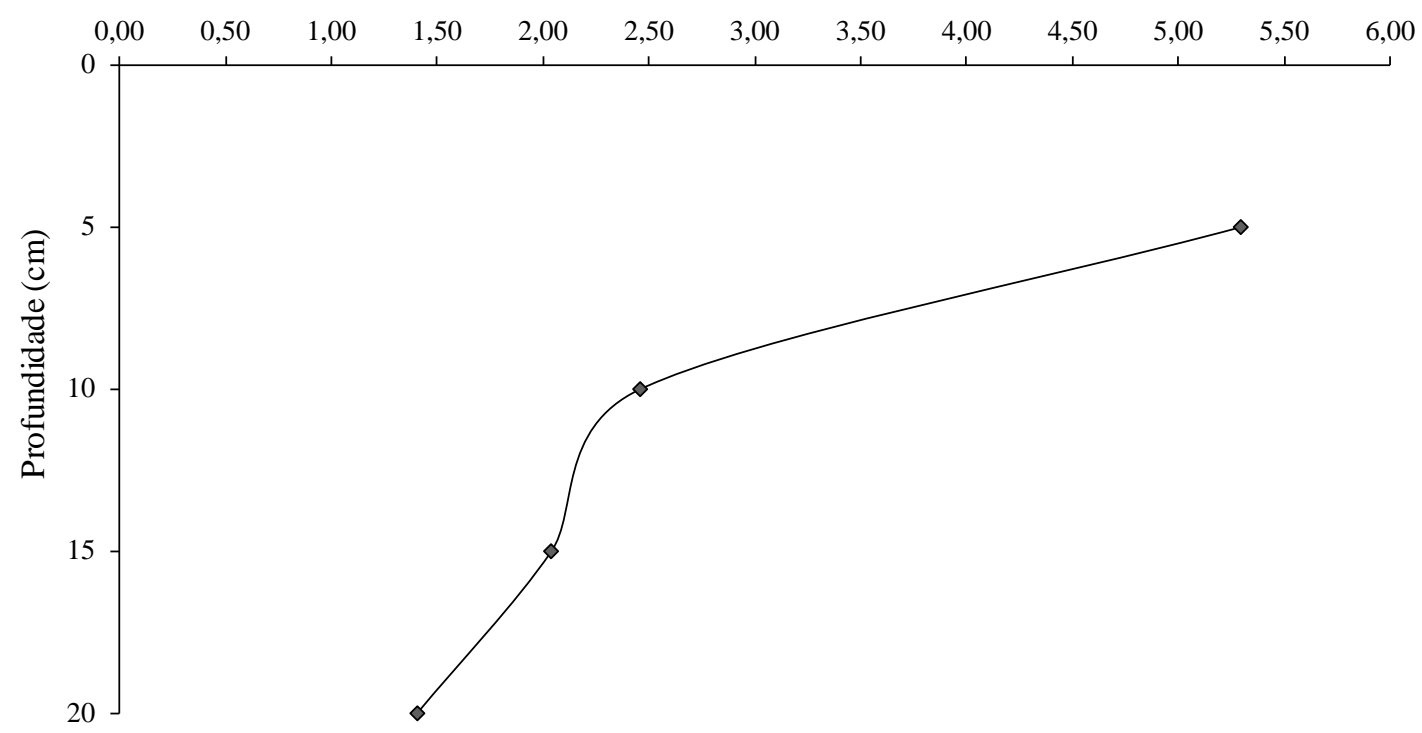

Figura 4. Densidade de raízes finas em profundidade na área de restauração florestal.

Foram encontrados 5,60 $\mathrm{Mg} \mathrm{ha}^{-1}$ de raízes finas nos primeiros $20 \mathrm{~cm}$ de profundidade. Desse total, quase a metade $(47,30 \%)$ se concentra nos primeiros $5 \mathrm{~cm}$ do solo (Tabela 2).

Tabela 2. Quantidade de biomassa de raízes finas em área de restauração florestal.

\begin{tabular}{ccc}
\hline $\begin{array}{c}\text { Profundidade } \\
\text { (cm) }\end{array}$ & \multicolumn{2}{c}{ Biomassa } \\
\cline { 2 - 3 } a 5 & $2,65 \mathrm{a}^{*}$ & $\mathbf{( \% )}$ \\
5 a 10 & $1,23 \mathrm{~b}$ & 47,30 \\
10 a 15 & $1,02 \mathrm{bc}$ & 21,95 \\
15 a 20 & $0,70 \mathrm{c}$ & 18,21 \\
Total & 5,60 & 12,54 \\
\hline
\end{tabular}

*Médias seguidas pela mesma letra na coluna não diferem entre si pelo teste de Tukey ao nível de $5 \%$ de probabilidade de erro.

Na Tabela 2, observa-se que os valores de biomassa decresceram gradativamente com o aumento da profundidade, passando de 2,65 $\mathrm{Mg} \mathrm{ha}^{-1}$ na camada de 0 a $5 \mathrm{~cm}$ para $0,70 \mathrm{Mg} \mathrm{ha}^{-1}$ na camada de 15 a $20 \mathrm{~cm}$.

Os valores estimados para densidade e biomassa de raízes finas nos primeiros 20 $\mathrm{cm}$ de profundidade, apresentam-se, de maneira geral, superiores aos encontrados por outros autores. Witschoreck et al. (2003), estimando a biomassa e comprimento de raízes finas de Eucalyptus urophylla com 10 anos de idade no município de Santa Maria - RS, encontraram 1,45 $\mathrm{Mg} \mathrm{ha}^{-1}$ até $60 \mathrm{~cm}$, sendo que 57,9 \% estavam concentrados nos primeiros $20 \mathrm{~cm}$ de profundidade. 
Navroski et al. (2010), estudando raízes finas em um povoamento de Eucalyptus cloeziana, encontraram 2,53 $\mathrm{g} \mathrm{dm}^{-3}$ e 1,27 $\mathrm{Mg} \mathrm{ha}^{-1}$ para densidade e biomassa, respectivamente, até $20 \mathrm{~cm}$ de profundidade. Avaliando a biomassa radicular em uma floresta secundária em estágio médio de estratificação no Município de Pinheiral-RJ, Menezes et al. (2010) encontraram, no período de verão, 1,88 Mg ha-1.

Esta diferença na biomassa radicular, relatada por diversos autores, pode ser atribuída, entre outros fatores, às diferentes condições ambientais em que os estudos foram conduzidos. No caso do presente estudo, a contaminação da área por espécies exóticas invasoras se torna um fator decisivo. A presença destas espécies, que possuem elevado potencial de adaptação e de crescimento, promovem expressivas mudanças no ambiente, como nos ciclos biogeoquímicos e na estrutura radicular do ecossistema (Hortal et al., 2010).

\section{Comprimento de raízes finas}

Os dados relativos ao comprimento de raízes finas diminuíram com o aumento da profundidade, apresentando o mesmo comportamento da densidade e biomassa. Observase que houve um decréscimo de $8,59 \mathrm{~cm} \mathrm{~cm}^{-3}$, na camada de $0-5 \mathrm{~cm}$, para $3,15 \mathrm{~cm} \mathrm{~cm}^{-3}$, na camada de 15-20 cm (Figura 5).

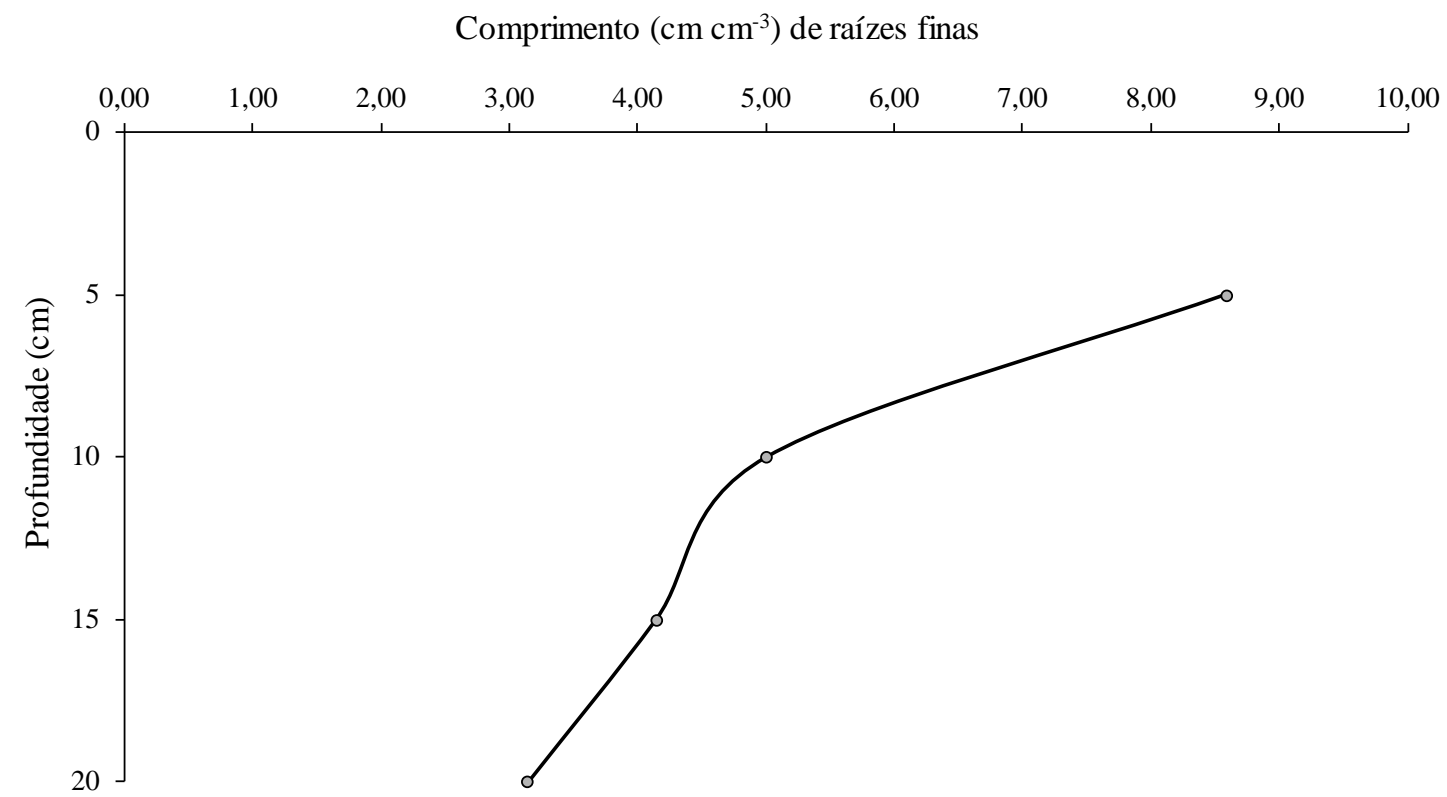

Figura 5. Comprimento de raízes finas em profundidade na área de restauração florestal.

A ocorrência de raízes finas está diretamente relacionada às características físicas e químicas das diferentes camadas que ocorrem ao longo do perfil do solo. No local de estudo observa-se, a partir dos dados de solo, maior quantidade de argila no horizonte B em comparação ao A (740 e $320 \mathrm{~g} \mathrm{~kg}^{-1}$, respectivamente). Esse maior teor de argila promove o maior adensamento das camadas inferiores, dificultando a penetração e o crescimento das raízes em profundidade.

Além disso, a maior concentração de $\mathrm{Al}^{3+}$ no horizonte $\mathrm{B}$ pode influenciar diretamente o crescimento do sistema radicular nesse perfil, tornando-as menos densas 
em profundidade. Isto se deve pelo fato do $\mathrm{Al}^{3+}$, quando em contato com as raízes, promover a paralisação imediata do seu crescimento, atrofiando-as em função da morte ou injúria do meristema radicular (Zonta et al., 2006).

De acordo com Witschoreck et al. (2003), a presença da serapilheira favorece a ocorrência de raízes nas primeiras camadas de solo, pois funciona como um isolante térmico, evitando o superaquecimento do solo e a perda de água por evapotranspiração. Além disso, esse padrão de distribuição vertical de raízes é comum para a maioria dos ecossistemas, principalmente em florestas tropicais, onde, na escassez de nutrientes em solos com alto grau de lixiviação, as raízes buscam os nutrientes provenientes da serapilheira.

Na Tabela 3, estão apresentados os comprimentos de raízes finas encontrados na área de estudo, sendo que, até a profundidade de $20 \mathrm{~cm}$, foram quantificados 104.435,81 $\mathrm{km} \mathrm{ha}^{-1}$.

Tabela 3. Comprimento de raízes finas $\left(\mathrm{km} \mathrm{ha}^{-1}\right)$ na área de restauração florestal.

\begin{tabular}{|c|c|c|}
\hline \multirow{2}{*}{$\begin{array}{c}\text { Profundidade } \\
\text { (cm) }\end{array}$} & \multicolumn{2}{|c|}{ Comprimento de raízes finas } \\
\hline & $\left(\mathrm{km} \mathrm{ha}^{-1}\right)$ & $(\%)$ \\
\hline 0 a 5 & $42.959,55 \mathrm{a}$ & 41,13 \\
\hline 5 a 10 & $25.026,71 \mathrm{~b}$ & 23,96 \\
\hline 10 a 15 & $20.717,06 \mathrm{bc}$ & 19,84 \\
\hline 15 a 20 & $15.732,49 \mathrm{c}$ & 15,06 \\
\hline Total & $104.435,81$ & 100 \\
\hline
\end{tabular}

* Médias seguidas pela mesma letra na coluna não diferem entre si pelo teste de Tukey ao nível de $5 \%$ de probabilidade de erro.

De maneira geral, verifica-se, no presente estudo, valores superiores em comparação com outros estudos, no que diz respeito ao comprimento de raízes finas. Navroski e Schumacher (2007), quantificando o comprimento de raízes finas em uma Floresta Estacional Decidual, encontraram cerca de $55 \mathrm{~km} \mathrm{ha}^{-1}$ até $45 \mathrm{~cm}$ de profundidade. Quantificando o comprimento de raízes finas em um povoamento de Pinus taeda L., LOPES et al. (2010) encontraram $68.412 \mathrm{~km} \mathrm{ha}^{-1}$ até $40 \mathrm{~cm}$ de profundidade.

Essas diferenças estão relacionadas, principalmente, pela ocupação da área pelas espécies exóticas. Este grupo de plantas, a partir do momento em que ingressa em uma determinada área, altera significativamente sua estrutura, incluindo o sistema radicular nesses ambientes. Isto ocorre porque essas espécies apresentam maior potencial de crescimento em comparação às espécies nativas, acumulando maiores quantidades de biomassa (Silva et al., 2018).

\section{Conclusões}

Os valores de biomassa e comprimento de raízes finas $\left(5,60 \mathrm{Mg} \mathrm{ha}^{-1}\right.$ e 104.435,81 $\mathrm{km} \mathrm{ha}^{-1}$, respectivamente) na área de restauração apresentaram-se elevados.

Com o aumento da profundidade do solo, a quantidade de raízes finas reduziu de $5,29 \mathrm{~g} \mathrm{dm}^{-3}$ nos primeiros $5 \mathrm{~cm}$ para $1,40 \mathrm{~g} \mathrm{dm}^{-3}$ na profundidade de $15-20 \mathrm{~cm}$. 


\section{Conflito de interesses}

Os autores declaram não haver conflito de interesses.

\section{Referências}

Alvares, C. A.; Stape, J. L.; Sentelhas, P. C.; Gonçalves, J. L. M.; Sparovek, G. Köppen's climate classification map for Brazil. Meteorologische Zeitschrift, v. 22, n. 6, p. 711-728, 2014. https://doi.org/10.1127/0941-2948/2013/0507

Farias, J. A. C.; Teixeira, I. F.; Pes, L.; Filho, A. A. Estrutura fitossociológica de uma floresta estacional decidual na região de Santa Maria, RS. Ciência Florestal, v. 4, n. 1, p. 109-128, 1994. https://doi.org/10.5902/19805098301

Finér, L.; Ohashib, M.; Noguchic, K.; Hiranod, Y. Factors causing variation in fine root biomass in forest ecosystems. Forest Ecology and Management, v. 261, p. 265-277, 2011. https://doi.org/10.1016/j.foreco.2010.10.016

Genet, M.; Stoke S, A.; Fourcaud, T.; Norris, J. E. The influence of plant diversity on slope stability in a moist evergreen deciduous forest. Ecological Engineering, v. 36. p. 265-275, 2010. https://doi.org/10.1016/j.ecoleng.2009.05.018

Gonçalves, J. L. M.; Mello, S. L. M. 0 sistema radicular das árvores. In: Gonçalves, J. L. M.; Benedetti, V. (Eds.). Nutrição e fertilização florestal. Piracicaba: IPEF/ESALQ/USP, 2005. p. 221-267.

Grant, J. C.; Nichols, J. D.; Yao R. L.; Smith, R. G. B.; Brennan, P. D. Vanclay, J. K. Depth distribution of roots of Eucalyptus dunnii and Corymbia citriodora subsp. variegata in different soil conditions. Forest Ecology and Management, v. 269, p. 249-258, 2012. https://doi.org/10.1016/j.foreco.2011.12.033

Hortal, J.; Borges, P. A.; Jiménez-Valverde, A.; Azevedo, E. B.; Silva, L. Assessing the areas under risk of invasion within islands through potential distribution modelling: The case of Pittosporum undulatum in São Miguel, Azores. Journal for Nature Conservation, v. 18, n. 4, p. 247-257, 2010. https://doi.org/10.1016/j.jnc.2009.11.002

Hughes, R. F.; Denslow, J. S. Invasion by a $\mathrm{N}_{2}$-fixing tree alters function and structure in wet lowland forests of Hawaii. Ecological Applications, v. 15, p. 1615-1628, 2005. https://doi.org/10.1890/04-0874

INMET - Instituto Nacional de Meteorologia. 2020. Disponível em: <http://www.inmet.gov.br/>. Acesso em: 17 fev. 2020.

Longhi, S. J.; Araujo, M. M.; Kelling, M. B.; Hoppe, J. M.; Müller, I.; Borsoi, G. A. Aspectos fitossociológicos de fragmento de Floresta Estacional Decidual, Santa Maria, RS. Ciência Florestal, v. 10, n. 2, p. 59-74, 2000. https://doi.org/10.5902/19805098471

Lopes, V. G.; Schumacher, M. V.; Calil, F. N.; Viera, M.; Witschoreck, R. Quantificação de raízes finas em um povoamento de Pinus taeda L. e uma área de campo em Cambará do $\begin{array}{llllll}\text { Sul, RS. Ciência } & \text { Florestal, } & \text { v. 20, } & \text { n. 4, } & \text { p. 569-578, }\end{array}$ https://doi.org/10.5902/198050982415

Lopes, V. G.; Schumacher, M. V.; Müller, I.; Calil, F. N.; Witschoreck, R.; Liberalesso E. Variáveis físicas e químicas do solo importantes na distribuição de raízes finas em um povoamento de Pinus taeda L. no nordeste do Rio Grande do Sul. Ecologia e Nutrição Florestal, v. 1, n. 1, p. 14-23, 2013. https://doi.org/10.13086/2316-980x.v01n01a02 
Menezes, C. E. G.; Pereira, M. G.; Correia, M. E. F.; Anjos, L. H. C.; Paula, R. R.; Souza, M. E. Aporte e decomposição da serapilheira e produção de biomassa radicular em florestas com diferentes estágios sucessionais em pinheiral, RJ. Ciência Florestal, v. 20, n. 3, p. 439-452, 2010. https://doi.org/10.5902/198050982059

Navroski, M. C.; Biali, L. J.; Bianchin, J. E.; Camargo, L.; Schumacher, M. V. Quantificação de biomassa e comprimento de raízes finas em povoamento de Eucalyptus cloeziana F. Muell. Revista Brasileira de Ciências Agrárias, v. 5, n. 4, p. 535-540, 2010. https://www.doi.org/10.5039/agraria.v5i4a725

Navroski, M. C.; Schumacher, M. V. Quantificação do comprimento de raízes de uma Floresta Estacional Decidual na região de Itaara, RS, Brasil. Santa Maria: UFSM/FATECIENS, Departamento de Ciências Florestais, 2007. (Relatório Técnico).

Nogueira, M. O.G. Estoque de carbono na biomassa radicular e no solo em ecossistema florestal em processo de recuperação. Lavras: Universidade Federal de Lavras, 2013. (Tese de doutorado).

Paiva, A. O.; Rezende, A. V.; Pereira, R. S. Estoque de carbono em cerrado sensu stricto do Distrito Federal. Revista Árvore, v. 35, p. 527-538, 2011. https://doi.org/10.1590/S0100-67622011000300015

Pedron, F. A.; Zago, A.; Dalmolin, R. S. D. Análise pedológica e caracterização paisagística do Jardim Botânico da Universidade Federal de Santa Maria através do sistema de informações geográficas. Revista Brasileira de Agrociências, v. 10, p. 219-225, 2004. https://doi.org/10.18539/cast.v10i2.947

Peltzer, D. A.; Kurokawa, H.; Wardle, D. A. Soil fertility and disturbance interact to drive contrasting responses of co-occurring native and nonnative species. Ecology, v. 97, n. 2, p. 515-529, 2016. https://doi.org/10.1890/15-0298.1

Richardson, D. M.; Pyšek, P. Naturalization of introduced plants: Ecological drivers of biogeographic pattern. New Phytologist, v. 196, n. 2, p.383-396, 2012. https://doi.org/10.1111/j.1469-8137.2012.04292.x

Santos, V. T.; Canto-Dorow, T. S.; Eisinger, S. M. Composição florística do componente herbáceo do Jardim Botânico da UFSM, Santa Maria, Rio Grande do Sul. Ciência e Natura, v. 32, n. 2, p. 61-82, 2010. https://doi.org/10.5902/2179460X9486

Silva, L. B.; Lourenço, P.; Teixeira, A.; Azevedo, E. B.; Alves, M.; Elias, R. B.; Silva, L. Biomass valorization in the management of woody plant invaders: The case of Pittosporum undulatum in the Azores. Biomass and Bioenergy, v. 109, p. 155-165, 2018. https://doi.org/10.1016/j.biombioe.2017.12.025

Vilà, M.; Espinar, J. L.; Hejda, M.; Hulme, P. E.; Jarošik, V.; Maron, J. L.; Pergl, J.; Schaffner, U.; Sun, Y.; Pyšek, P. Ecological impacts of invasive alien plants: A meta-analysis of their effects on species, communities and ecosystems. Ecology Letters, v. 14, p. 702-708, 2011. https://doi.org/10.1111/j.1461-0248.2011.01628.x

Wardle, D. A.; Peltzer, D. A. Impacts of invasive biota in forest ecosystems in an aboveground-belowground context. Biological Invasions, v. 19, n. 11, p. 3301-3316, 2017. https://doi.org/10.1007/s10530-017-1372-x

Witschoreck, R.; Schumacher, M. V.; Caldeira, M. V. W. Estimativa da biomassa e do comprimento de raízes finas em Eucalyptus urophylla S.T. Blake no Município de Santa Maria, RS. Revista Árvore, v. 27, n. 2, p. 177-183, 2003. https://doi.org/10.1590/S010067622003000200008 
Zonta, E.; Brasil, F. C.; Goi, S. R.; Rosa, M. M. T. O sistema radicular e suas interações com o ambiente edáfico. In: Fernandes, M. S. (Ed.). Nutrição mineral de plantas. Viçosa: Sociedade Brasileira de Ciência do Solo, 2006. p. 7-52.

CC Anformação da Licença: Este é um artigo Open Access distribuído sob os termos da Licença Creative Commons seja devidamente citada. 